\title{
The anatomy and an illustrated description of a technique for combined laparoscopic and vaginal total removal of an obturator mid urethral tape
}

\author{
Tamsin Greenwell ${ }^{1}$, Alfred Cutner ${ }^{2}$ \\ ${ }^{1}$ Department of Urology, ${ }^{2}$ Department of Gynaecology, University College London Hospital, London, UK \\ Correspondence to: Tamsin Greenwell. Department of Urology, University College London Hospital, London, UK. Email: tamsin.greenwell@nhs.net; \\ Alfred Cutner. Department of Gynaecology, University College London Hospital, London, UK. Email: alfred.cutrner1@nhs.net.
}

\begin{abstract}
To date complete excision of a mid-urethral obturator tape has required vaginal and groin exploration-a morbid procedure. We detail the theoretical anatomy and describe the operative technique for the first ever combined laparoscopic and vaginal complete excision of mid-urethral obturator tape. This procedure was successfully performed in a 65-year-old female along with simultaneous laparoscopic redo colposuspension with complete removal of mid-urethral obturator tape and successful resolution of all symptoms including stress urinary incontinence. It is possible for an experienced laparoscopic and vaginal surgeon working in tandem to completely remove a mid-urethral obturator tape without the need for groin dissection. This is the first description of this technique.
\end{abstract}

Keywords: Mid-urethral obturator tape; removal; laparoscopic; vaginal

Submitted Jul 01, 2018. Accepted for publication Oct 15, 2018.

doi: $10.21037 /$ tau.2018.10.05

View this article at: http://dx.doi.org/10.21037/tau.2018.10.05

\section{Introduction}

Mid-urethral tapes for the management of stress urinary incontinence in women remain the commonest (1-3), the best studied $(4,5)$ and the most effective technique (5-7) with the fewest adverse events (7-10). However there has been an increasing number of women requiring or requesting tape removal for complications such as vaginal exposure, urethral extrusion, bladder extrusion and chronic pain issues $(11,12)$. There are reports of complete removal of retropubic mid-urethral tapes using either a laparoscopic or open technique $(13,14)$. However, to date complete removal of an obturator mid-urethral tape has required extensive open groin dissection combined with vaginal excision (15). We describe the anatomy related to insertion of obturator mid-urethral tapes and the first report of a combined laparoscopic and vaginal complete excision of a mid-urethral obturator tape.

\section{Anatomy}

The path of a mid-urethral obturator tape passes through the skin and subcutaneous fascia in the medial thigh and then through the obturator externus muscle (Figure 1), the obturator membrane and the obturator internus muscle (Figure 2). Throughout its course it remains below levator ani within the perineum. We postulated that it would be possible to enter the perineum laparoscopically medial to the obturator internus muscle by detachment of the anterior aspect of the tendinous arch (Figure 3).

This would allow retrieval of a mid-urethral obturator tape identified and divided vaginally and passed up into the pelvis medial to the obturator internus. It would then be theoretically possible to mobilise alongside the tape and free it from the obturator internus, obturator membrane, the obturator externus and the overlying fascia by a combination of blunt and sharp dissection along the tape. 


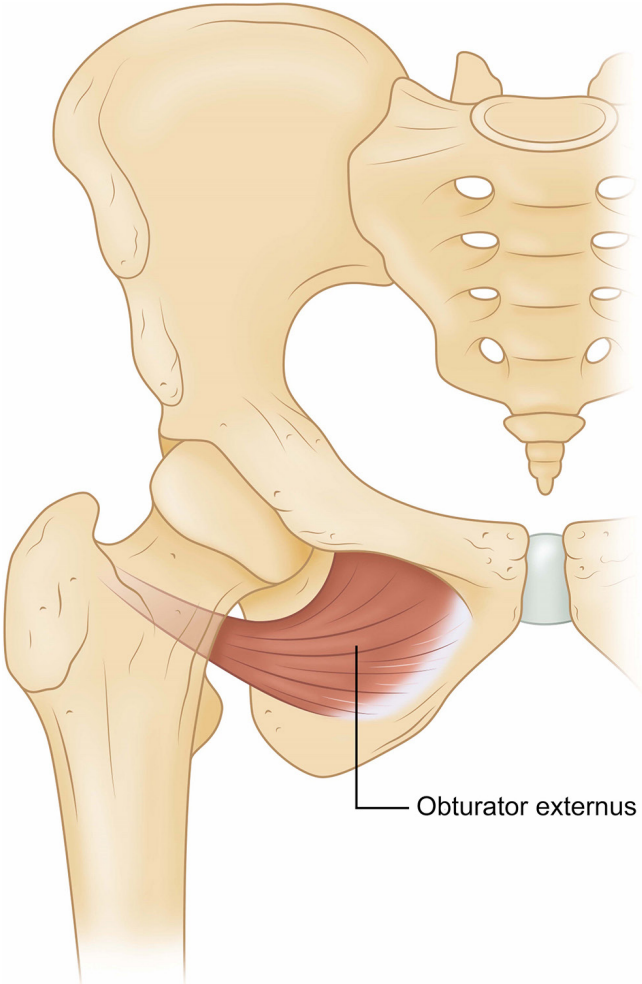

Figure 1 Obturator externus muscle.

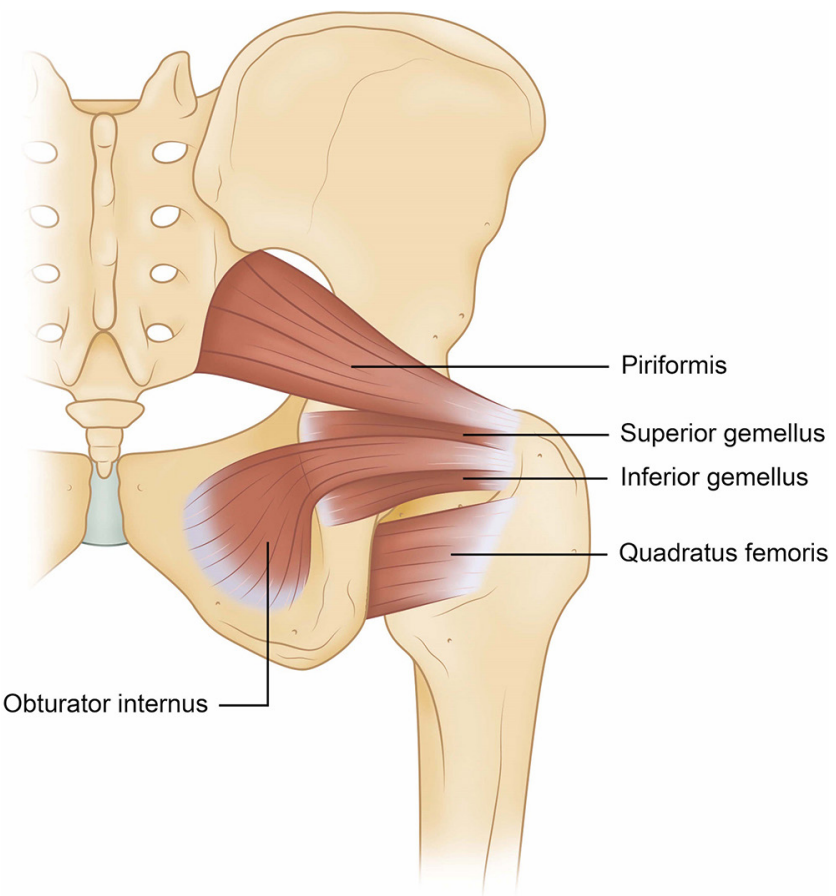

Figure 2 Obturator internus muscle.

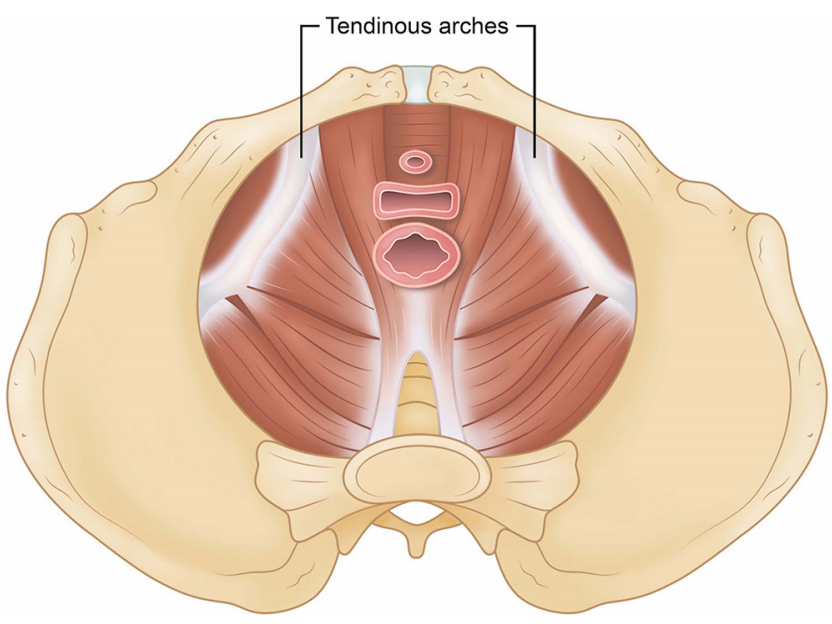

Figure 3 Levator ani and the tendinous arch.

\section{Patient and technique}

A 65 -year-old female presented with a longstanding history of mixed urinary incontinence and recurrent urinary tract infections (UTIs). She had an obturator mid-urethral tape inserted 10 years previously followed by a laparoscopic colposuspension 5 years previously in another hospital. She had urodynamically proven type $2 \mathrm{~b}$ stress urinary incontinence and computed tomography of kidneys, ureters, bladder (CT KUB) and cystoscopic evidence of a stone thought to be attached to an erosion of a previous colposuspension suture.

After a multidisciplinary team (MDT) discussion [in line with National Institute of C46,49linical Excellence (NICE) guidance] (16) and extensive discussion with the patient, a joint patient-surgeon decision was made to proceed with laparoscopic take down of the old ineffective colposuspension, vaginal removal of the obturator tape combined with laparoscopic removal of the perineal aspect of tape, vesicostomy, removal of suture and foreign body and redo- colposuspension.

This description relates only to the technique of combined laparoscopic and vaginal removal of the midurethral obturator tape.

The patient was placed in a modified lithotomy position on the operating table with her arms wrapped against her sides. She was cleaned and draped in a standard manner. Initial cystoscopy (surgeon A) was carried out to confirm the site and size of the intravesical foreign body and exclude any additional intra-vesical pathology. Bilateral 5F open-ended ureteric catheters (Cook UK Medical) were inserted and a 


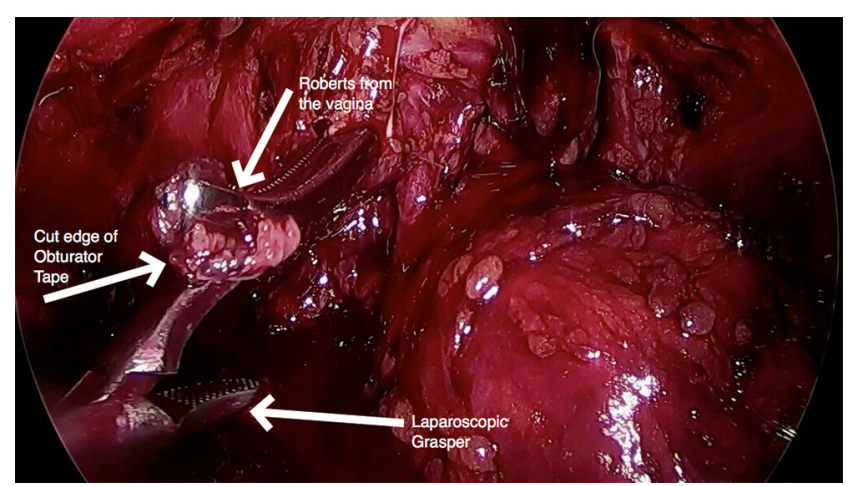

Figure 4 This demonstrates dissection below the pelvic floor into the perineum with the mobilised tape being passed from the vaginal aspect to the laparoscopic aspect. The bladder neck and the catheter balloon in the bladder is seen medial to the forceps.

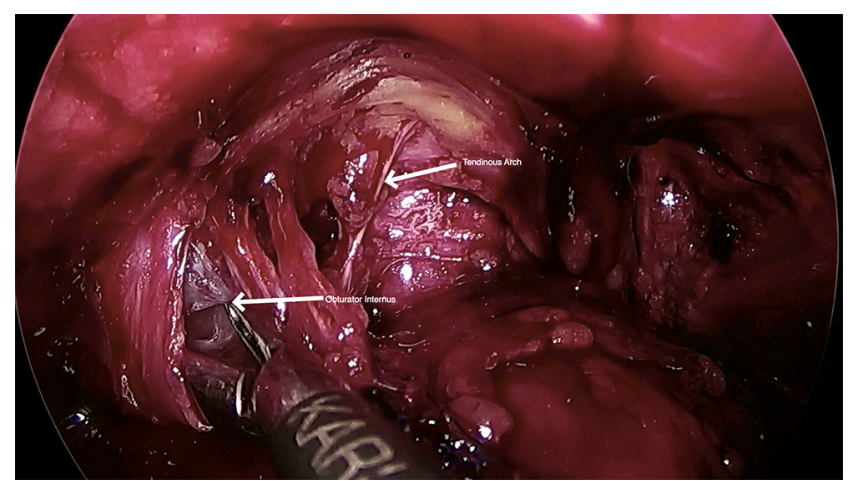

Figure 5 This demonstrates laparoscopic mobilisation of the tape through the obturator internus muscle using a combination of blunt and Thunderbeat ${ }^{\circledR}$ dissection.

$16 \mathrm{~F}$ urethral Foley catheter inserted to drain the bladder.

A pneumoperitoneum was obtained using a Veress needle at the umbilicus (surgeon B). A size $11 \mathrm{~mm}$ trocar was inserted into the umbilicus and the abdominal cavity inspected. A right lateral and a left lateral $5 \mathrm{~mm}$ trocar were inserted in line with the umbilicus about $8 \mathrm{~cm}$ from the midline. Thunderbeat ${ }^{\circledR}$ (Olympus Medical) was used as the energy source for the procedure. This utilises bipolar energy with ultracision for haemostatic cutting and a second mode of bipolar energy alone for haemostasis.

Initially the anterior peritoneum was incised to enable access the cave of Retzius. Both blunt dissection and Thunderbeat ${ }^{\circledR}$ were used to fully dissect the space down to the bladder neck such that the ileopectineal ligaments, paravaginal spaces and para-urethral spaces were cleared. At this point a further $11 \mathrm{~mm}$ suprapubic port was inserted 2 to $3 \mathrm{~cm}$ above the pubic hairline.

As part of the planned procedure, the old colposuspension was taken down, the tendinous arch mobilised and the perineum entered from above. This enabled views of the internal aspect of obturator internus muscle bilaterally.

The vaginal tissue was then infiltrated with Marcaine and Adrenalin (surgeon A). The vagina was incised in the midline and mobilised off the underlying peri-urethral tissues and the mid-urethral tape. The tape was mobilised off the underlying urethra, divided in the midline and fully mobilised bilaterally to its vaginal limits.

The tape was passed, at this point, from the vagina by surgeon A through to the abdominoperineal cavity immediately medial to the internal aspect of obturator internus into the laparoscopic graspers of surgeon B (Figure 4).

The tape was then followed along to the obturator muscle identifying its point of perforation. The tape was mobilised with a combination of blunt and Thunderbeat ${ }^{\circledR}$ dissection to open the plane and achieve haemostasis along the path of the obturator tape through the obturator internus muscle (Figure 5).

The dissection was continued until the tape pulled free of the muscle and the tape was cut as flush as possible with the subcutaneous tissue removing it in its entirety. The process was then repeated on the other side.

After the tape removal, a laparoscopic vesicostomy and removal of a foreign body and eroding colposuspension suture plus redo colposuspension was performed as planned. The ports were removed in a standard manner and the port sites closed with fascial sutures for the $11 \mathrm{~mm}$ ports with a 0 Vicryl ${ }^{\circledR}$ (polyglactin) suture (Ethicon, West Somerville, USA). The skin was closed with $3 / 0$ Vicryl ${ }^{\circledR}$ (polyglactin) suture (Ethicon). The vagina was closed using $3 / 0$ Vicryl ${ }^{\circledR}$ (polyglactin) suture (Ethicon). She was discharge home after 2 nights in hospital.

In this case the Foley catheter was left in situ for 3 weeks when a cystogram confirmed bladder healing and she had a successful trial of void. For an uncomplicated procedure without vesicostomy removal of the catheter would be planned for day 1 or 2 post-surgery depending on patient mobility.

The patient was reviewed at 6 weeks post-surgery. At this stage she was voiding spontaneously, had no stress urine leakage, had had no UTIs and was pain free. 


\section{Conclusions}

We detail and illustrate the anatomy and the technique for successful complete removal of an obturator mid-urethral tape using a combined laparoscopic and vaginal approach. This surgery requires 2 experienced surgeons operating in tandem. One requires experience of complex vaginal dissection and tape mobilisation whilst the other requires experience in complex laparoscopic surgery. This technique of obturator tape removal has never before been described and we would advocate the use of this technique instead of formal groin dissection when complete removal of an obturator tape is required.

\section{Acknowledgements}

None.

\section{Footnote}

Conflicts of Interest: The authors have no conflicts of interest to declare.

Informed Consent: We confirm we have written permission from the patient for this publication.

\section{References}

1. Department of Health, UK. Hospital Episode Statistics. 2016. Available online: http://www.hesonline.nhs.uk

2. Department of Health, UK. Hospital Episode Statistics. 2015. Available online: http://www.hesonline.nhs.uk

3. Department of Health, UK. Hospital Episode Statistics. 2014. Available online: http://www.hesonline.nhs.uk

4. Manach Q, Bouquot M, Rouprêt M, et al. Placement of tension-free vaginal tape in women with stress urinary incontinence: Long-term functional outcomes in a prospective series. Prog Urol 2017;27:640-6.

5. Ford AA, Rogerson L, Cody JD, et al. Mid-urethral sling operations for stress urinary incontinence in women. Cochrane Database Syst Rev 2017;7:CD006375.

6. Lier D, Robert M, Tang S, et al. Surgical treatment of stress urinary incontinence-trans-obturator tape compared with tension-free vaginal tape-5-year follow up: an economic evaluation. BJOG 2017;124:1431-9.

7. Schimpf MO, Rahn DD, Wheeler TL, et al. Sling surgery for stress urinary incontinence in women: a systematic review and metaanalysis. Am J Obstet Gynecol 2014;211:71.e1-27.

8. Fusco F, Abdel-Fattah M, Chapple CR, et al. Updated Systematic Review and Meta-analysis of the Comparative Data on Colposuspensions, Pubovaginal Slings, and Midurethral Tapes in the Surgical Treatment of Female Stress Urinary Incontinence. Eur Urol 2017;72:567-91.

9. Song $\mathrm{P}$, Wen $\mathrm{Y}$, Huang $\mathrm{C}$, et al. The efficacy and safety comparison of surgical treatments for stress urinary incontinence: A network meta-analysis. Neurourol Urodyn 2018;37:1199-211.

10. Leone Roberti Maggiore U, Finazzi Agrò E, Soligo M, et al. Long-term outcomes of TOT and TVT procedures for the treatment of female stress urinary incontinence: a systematic review and meta-analysis. Int Urogynecol J 2017;28:1119-30.

11. Forzini T, Viart L, Alezra E, et al. Erosive complications of mid urethral slings (MUS): 10 years of surgical experience. Prog Urol 2015;25:240-8.

12. Miklos JR, Chinthakanan O, Moore RD, et al. Indications and Complications Associated with the Removal of 506 Pieces of Vaginal Mesh Used in Pelvic Floor Reconstruction: A Multicenter Study. Surg Technol Int 2016;29:185-9.

13. Grange P, Shakir F, Thiagamoorthy G, et al. Technical Video: Vesicoscopic Excision of Eroded Tension-free Vaginal Tape. J Minim Invasive Gynecol 2016;23:676.

14. Rigaud J, Pothin P, Labat JJ, et al. Functional results after tape removal for chronic pelvic pain following tension-free vaginal tape or transobturator tape. J Urol 2010;184:610-5.

15. Reynolds WS, Kit LC, Kaufman MR, et al. Obturator foramen dissection for excision of symptomatic transobturator mesh. J Urol 2012;187:1680-4.

16. National Institute of Clinical Excellence. Urinary incontinence in women: management. Available online: https://www.nice.org.uk/guidance/CG171

Cite this article as: Greenwell T, Cutner A. The anatomy and an illustrated description of a technique for combined laparoscopic and vaginal total removal of an obturator mid urethral tape. Transl Androl Urol 2018;7(6):978-981. doi: 10.21037/tau.2018.10.05 